\title{
The Effect of Contact-Drying on Physical Properties of European Beech (Fagus sylvatica L.)
}

\author{
Ivan Klement *, Peter Vilkovský * and Tatiana Vilkovská * \\ Department of Wood Technology, Faculty of Wood Sciences and Technology, Technical University in Zvolen, T. \\ G. Masaryka 24, 96001 Zvolen, Slovakia \\ * Correspondence: klement@tuzvo.sk (I.K.); xvilkovsky@tuzvo.sk (P.V.); tatiana.vilkovska@gmail.com (T.V.); \\ Tel.: +421-45-520-6376
}

Received: 10 July 2020; Accepted: 14 August 2020; Published: 16 August 2020

\begin{abstract}
Beech wood is mainly used for furniture, plywood, decorative veneer manufacturing or packaging. Timber or lumber is traditionally dried in kilns by processes often taking several weeks. This research deals with more rapid process called contact-drying process. Drying was performed using the heating plates with a temperature of $160^{\circ} \mathrm{C}$ and pressures of $1.0 \mathrm{MPa}, 1.4 \mathrm{MPa}$ and $1.8 \mathrm{MPa}$. The results were compared to conventional warm-air drying. The warm-air drying mode was divided into two phases, with and without free water and bound water in the dried wood. The density of the samples increased remarkably during the contact-drying. The effect of the pressure of the heating plates was substantial. The difference in the average density between the pressure of $1.0 \mathrm{MPa}$ and $1.8 \mathrm{MPa}$ was more than $22 \mathrm{~kg} \cdot \mathrm{m}^{-3}$. The pressure of the heating plates affected the process and the resulting change in the sample thickness. The change in the sample thickness was more considerable in the case of the tangential samples. The thickness did not increase significantly after air conditioning. During contact-drying, the hygroscopicity and absorptivity of wood reduced on average by $21.24 \%$ and $25 \%$, respectively, compared to warm-air drying.
\end{abstract}

Keywords: contact-drying; beech wood; hygroscopicity of wood; absorptivity of wood; physical properties

\section{Introduction}

European beech (Fagus sylvatica L.) is an important tree species with a rather large distribution in the countries of Western and Central Europe [1]. Beech wood is mainly used for furniture, plywood, decorative veneer manufacturing or parquet (flooring). Most lumber must be dried prior to its use since drying reduces shrinkage, increases strength, reduces weight and improves overall manufacturing quality [2]. Timber or lumber is traditionally dried in kilns by processes often taking several weeks. Several methods have been proposed to increase the drying rate over the years. Several ways to reduce the drying time from weeks to hours [3], for example contact-drying, high frequency drying, and so forth are known in the world. Contact-drying is a method when wood is exposed to compression forces from heated platens with the purpose of increasing the moisture loss and reducing warp [4]. It is usually dried by demonstrated schedules of a temperature and relative humidity specific for each tree species and lumber thickness [5]. In the case of deciduous tree species, the pressure from 0.4 up to $2.5 \mathrm{MPa}$ is used. The temperature during contact-drying should be in the range between 160 and $170{ }^{\circ} \mathrm{C}$. Even higher temperatures were used in the research [6,7] on drying various deciduous tree species. Physical [7,8] and mechanical properties of wood [8,9] changed during contact-drying process. These changes in selected physical properties (density, hygroscopicity of wood, etc.) were confirmed by several authors [5-7,9] Observations of the authors [5,9] showed that the density mainly in the surface layers of the samples increased as a result of the contact-drying.. Other changes in 
physical properties were mentioned in the research of poplar wood $[10,11]$ where a decrease in the hygroscopicity of wood by contact-drying process was demonstrated. Moreover, the pressure from heated platens resulted in the changes in the sample dimensions during contact-drying. Based on the work [12], an increase in the density by even $10 \%$ has been discovered due to contact-drying These changes are also confirmed by the works [7,12], in which a change-especially in the sample thickness-was found. The author [7,12] discovered that contact-dried wood is approximately 30 up to 60 percent more stable in width than kiln-dried wood, but in general, 10 to 80 percent less consistent in thickness. The objective of this research was to evaluate the effect of contact-drying process on the physical properties (moisture content, hygroscopicity of wood, absorptivity of wood) of beech wood with the use of different pressures 1, 1.4, 1.8 MPa.

\section{Material and Methods}

Beech wood (Fagus sylvatica L.) was used for the experimental measurements. The samples were chosen from two beech logs with a diameter of $40 \mathrm{~cm}$ and the length of $300 \mathrm{~cm}$. The forest is located in the part called Môt'ová (475 m ASL) and it is a part of the University Forest Enterprise of the Technical University in Zvolen, Slovakia. The radial and tangential samples were cut out (longitudinal and cross section sawing) from the log, according to sawing patterns (Figure 1). Dimensions of drying samples were $120 \times 800 \times 30 \mathrm{~mm}(\mathrm{w} \times 1 \times \mathrm{t})$. The samples were selected with sapwood without mature wood or false red heartwood. In total, 72 samples were investigated (36 radial and tangential samples, respectively).

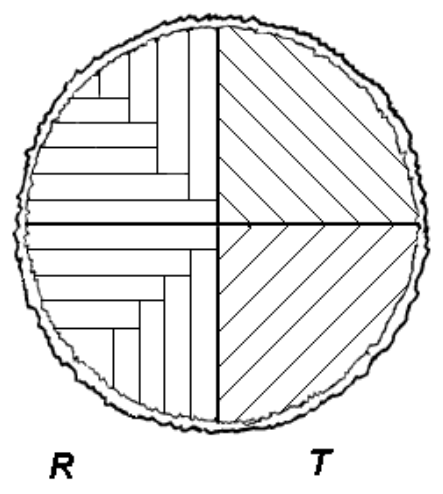

Figure 1. Sawing patterns to obtain radial and tangential samples.

The process of contact-drying was conducted in hydraulic single storied press type CBJ 500-5 (TOS RAKOVNIK) at the Department of Wood Technology, Technical University in Zvolen, Slovakia (Figure 2). A temperature of the heating plates was $160^{\circ} \mathrm{C}$ and three specific pressures of 1.0, 1.4 and 1.8 MPa were used. Drying with hydrothermal modification were combined in the process. It can be seen in the results obtained (the change in thickness, density and other parameters measured were used). The group of samples was dried until the temperature measured in the center of the sample reached the temperature of the pressing plate $\left(t_{p}+5{ }^{\circ} \mathrm{C}\right)$ after being inserted between the heating plates and reaching the specific pressure of the plates. Contact-drying in the press was completed after reaching this temperature. One group of samples (radial and tangential) was made always from one log. 


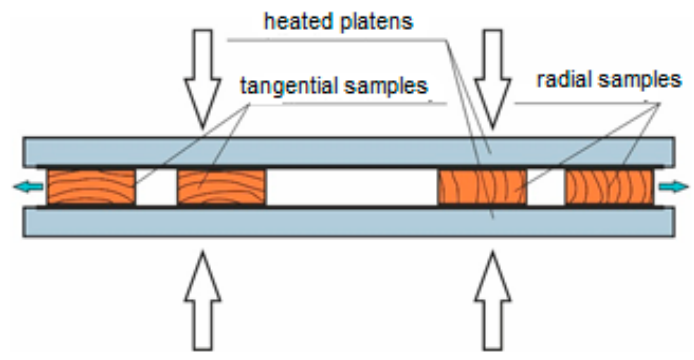

Figure 2. Scheme of sample storage during contact-drying.

The drying modes are shown in Figure 3. The development of temperatures in the individual phase of contact-drying are shown there. The samples started to be dried when a constant temperature of $160{ }^{\circ} \mathrm{C}$ (I., II. phase) was reached. The cooling phase was (III.) after reaching the temperature in the center of the samples. Air conditioning at $20^{\circ} \mathrm{C}$ was the last phase.

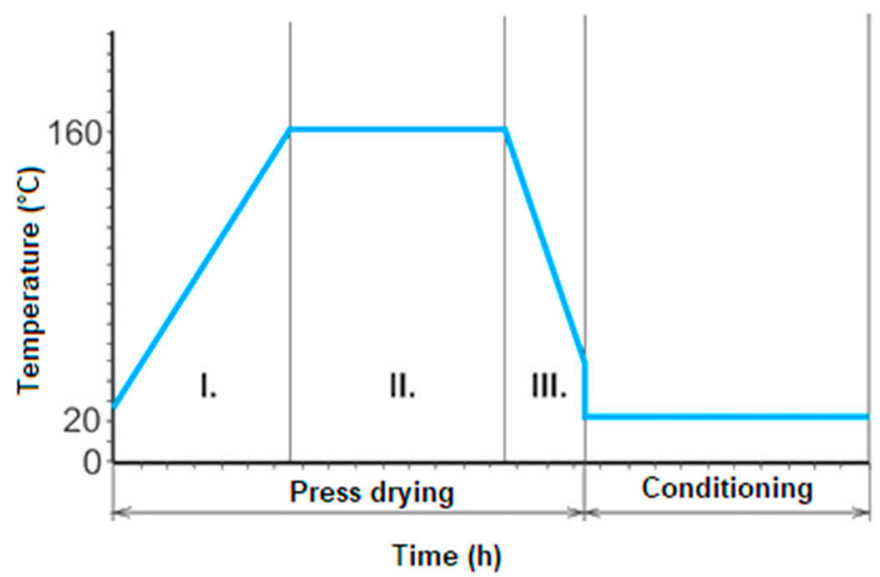

Figure 3. Contact-drying mode.

The selected samples were dried also with the warm-air drying process. The warm-air-drying mode was divided into two phases, with or with no free water and bound water in the dried wood. The first phase when drying process was above fiber saturation point (FSP), was drying at a temperature of $50{ }^{\circ} \mathrm{C}$ and $90 \%$ relative humidity. The second phase (under fiber-saturation point) was at a temperature of $50{ }^{\circ} \mathrm{C}$ and $54 \%$ relative humidity.

Thickness of the samples was measured prior to each contact-drying process. The samples were also cut to determine initial moisture content, moisture gradient and density as well (Figure 4).

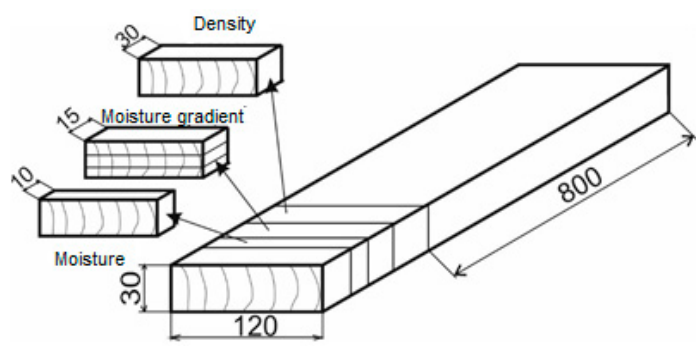

Figure 4. Method of selecting the samples.

Initial $\left(\mathrm{w}_{\mathrm{i}}\right)$ and final $\left(\mathrm{w}_{\mathrm{f}}\right)$ moisture content of wood was determined using the gravimetric method according to STN EN 49 0103. The moisture content was calculated using Equation (1):

$$
M C=\frac{m_{w}-m_{0}}{m_{0}} \cdot 100(\%)
$$


where: $m_{w}$ is the weight of the wet sample $(\mathrm{g})$ and $m_{0}$ is the weight of the absolutely dry sample $(\mathrm{g})$

Density in the oven-dried state was measured before and after drying. The measurement was performed under laboratory conditions. The density $\left(\rho_{0}\right)$ of wood at $0 \%$ moisture content was measured according to STN EN 49 0108. The oven-dried density was calculated using Equation (2),

$$
\rho_{0}=\frac{m_{0}}{V_{0}}\left(\mathrm{~kg} \cdot \mathrm{m}^{-3}\right)
$$

where: $m_{0}$ is the weight of oven-dried moisture samples $(\mathrm{kg})$ and $V_{0}$ is the volume of oven-dried moisture samples $\left(\mathrm{m}^{-3}\right)$.

All of the samples were measured before and after drying with moisture gradient. The samples were separated into layers. The moisture content of each layer was determined by the oven-dry method. The moisture gradient was calculated using Equation (3):

$$
\Delta \mathrm{w}=\mathrm{w}_{\mathrm{c}}-\left(\frac{\sum \mathrm{w}_{\mathrm{pov}}}{\mathrm{n}}\right) \quad(\%)
$$

where: $\Delta \mathrm{w}$ is the moisture gradient $(\%), \mathrm{w}_{\mathrm{c}}$ is the middle moisture content $(\%)$, and $\mathrm{w}_{\text {pov }}$ is the surface moisture content $(\%), \mathrm{n}$ is the number of layers.

The temperature was continuously measured during the whole contact-drying process. Temperature of the samples in contact-drying process $(1 / 6$ thickness under the surface and in the middle of sample) was measured using the Comet MS6R device and type $\mathrm{T}(\mathrm{Cu}-\mathrm{CuNi})$ thermocouples. According to the temperature, the contact-drying process was conducted.

Change in the thickness of the samples was measured at regular intervals with an accuracy of 0.01 $\mathrm{mm}$. The samples were placed in air-conditioning chamber at a temperature of $20^{\circ} \mathrm{C}$ and a relative humidity of $60 \%$ after contact-drying process. The thickness of the samples was measured again after conditioning (Figure 5).

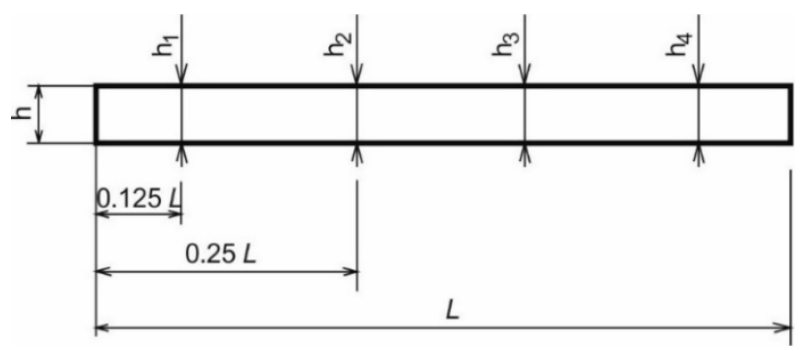

Figure 5. Scheme of measuring the thickness of samples.

\section{Hygroscopicity of wood}

Hygroscopicity of wood is characterized as the ability of wood to absorb air humidity from the environment. The hygroscopicity of wood was measured according to STN EN 490104 . Testing hygroscopicity of wood resulted from long-term storage in the environment with the required temperature $\left(20 \pm 3{ }^{\circ} \mathrm{C}\right)$ and relative humidity $(96 \%)$ kept by a saturated solution of Potassium phosphate monobasic (KH2PO4). Dimensions of the samples were $20 \times 20 \times 30 \mathrm{~mm}$. The samples were weighed after 1,2, 4 and $8 \mathrm{~h}$ and after 1,3, 5, 7, 14 and 28 days from the beginning of the measurement. The hygroscopicity of wood was calculated using Equation (4):

$$
M C_{r}=\frac{m_{r}-m_{0}}{m_{0}}(\%)
$$

where: $m_{r}$-the weight of the sample after reaching equilibrium moisture content in given environment, $m_{0}$-is the weight of the sample after drying $(\mathrm{g})$. 
The test was performed according to STN EN 49 0104. Testing the absorptivity of wood is based on immersing the absolutely dry samples in distilled water until the weight is stabilized. Samples were continuously weighed at an appointed time. The absorptivity of wood was calculated using Equation (5):

$$
M C_{\max }=\frac{m_{w}-m_{0}}{m_{0}}(\%)
$$

where: $m_{w}$ — the weight of the sample after dipping of samples $(\mathrm{g}), m_{0}$ - is the weight of the sample after drying $(\mathrm{g})$.

\section{Results and Discussion}

The average values of initial and final moisture content, drying time and moisture gradient of the samples are shown in Table 1.

Table 1. Average values of moisture content, drying times and moisture gradients of samples.

\begin{tabular}{|c|c|c|c|c|c|c|c|c|c|c|c|}
\hline \multirow{3}{*}{$\begin{array}{l}\text { Type of } \\
\text { Samples }\end{array}$} & \multirow{3}{*}{$\begin{array}{c}\text { Pressure } \\
\text { of Plates } \\
\text { (MPa) }\end{array}$} & \multicolumn{4}{|c|}{ Moisture Content w (\%) } & \multirow{2}{*}{\multicolumn{2}{|c|}{$\begin{array}{l}\text { Drying Time (min) } \\
\text { Contact-Drying }\end{array}$}} & \multicolumn{4}{|c|}{ Moisture Gradient $\Delta w(\%)$} \\
\hline & & \multicolumn{2}{|c|}{ Initial } & \multicolumn{2}{|c|}{ Final } & & & \multicolumn{2}{|c|}{ Before Drying } & \multicolumn{2}{|c|}{ After Drying } \\
\hline & & Mean & $\begin{array}{l}\text { Standard } \\
\text { Deviation }\end{array}$ & Mean & $\begin{array}{l}\text { Standard } \\
\text { Deviation }\end{array}$ & Mean & $\begin{array}{l}\text { Standard } \\
\text { Deviation }\end{array}$ & Mean & $\begin{array}{l}\text { Standard } \\
\text { Deviation }\end{array}$ & Mean & $\begin{array}{l}\text { Standard } \\
\text { Deviation }\end{array}$ \\
\hline \multirow{2}{*}{$\mathbf{R}$} & 1.0 & 77.48 & 1.126 & 3.95 & 0.23 & 80 & 0.935 & 4.54 & 0.572 & 4.00 & 0.245 \\
\hline & 1.4 & 80.27 & 0.948 & 6.08 & 0.44 & 80 & 1.085 & 1.39 & 0.205 & 8.46 & 0.286 \\
\hline \multirow{3}{*}{$\mathrm{T}$} & 1.0 & 71.87 & 0.549 & 5.78 & 0.326 & 100 & 1.21 & 1.88 & 0.245 & 8.98 & 0.318 \\
\hline & 1.4 & 54.14 & 0.816 & 5.37 & 0.849 & 110 & 0.973 & 1.93 & 0.327 & 9.84 & 0.572 \\
\hline & 1.8 & 55.54 & 1.14 & 4.87 & 0.489 & 90 & 1.195 & 5.69 & 0.980 & 3.19 & 0.351 \\
\hline
\end{tabular}

The measurements of values showed that the effect of the pressure of press machine on the drying time of the samples is not relevant (Table 1). Based on Table 1, it can be seen that the drying time resulting from contact-drying is considerably shorter compared to warm-air-drying. The warm-air-drying process took 6480 min of drying time. Comparing to the time of the contact-drying, the time of drying process is considerably longer. Short time of drying was confirmed even by other works [3,10]. Small differences in time of drying between the radial and tangential samples were discovered. The radial samples were dried quickly compared to the tangential samples. The biggest difference of $30 \mathrm{~min}$ was observed in drying time. It can be seen in Table 1. The difference was likely due to the fact that the tangential samples were dried more slowly compared to the radial samples. It relates to the higher diffusion coefficient in the radial direction compared to the diffusion coefficient in the tangential direction. It resulted in longer time of drying mainly in the case of the tangential samples [5].

The difference in the values of moisture gradient before drying between the radial and tangential samples was observed. The measured values of the moisture gradients were high, although the average values of final moisture content after drying were low. The changes in moisture content in the cross section of the dried samples and the necessary stage of air conditioning are demonstrated. The average density of the radial and tangential samples in absolute dry state after contact-drying process at individual pressures of the heating plates are shown in Figure 6. 


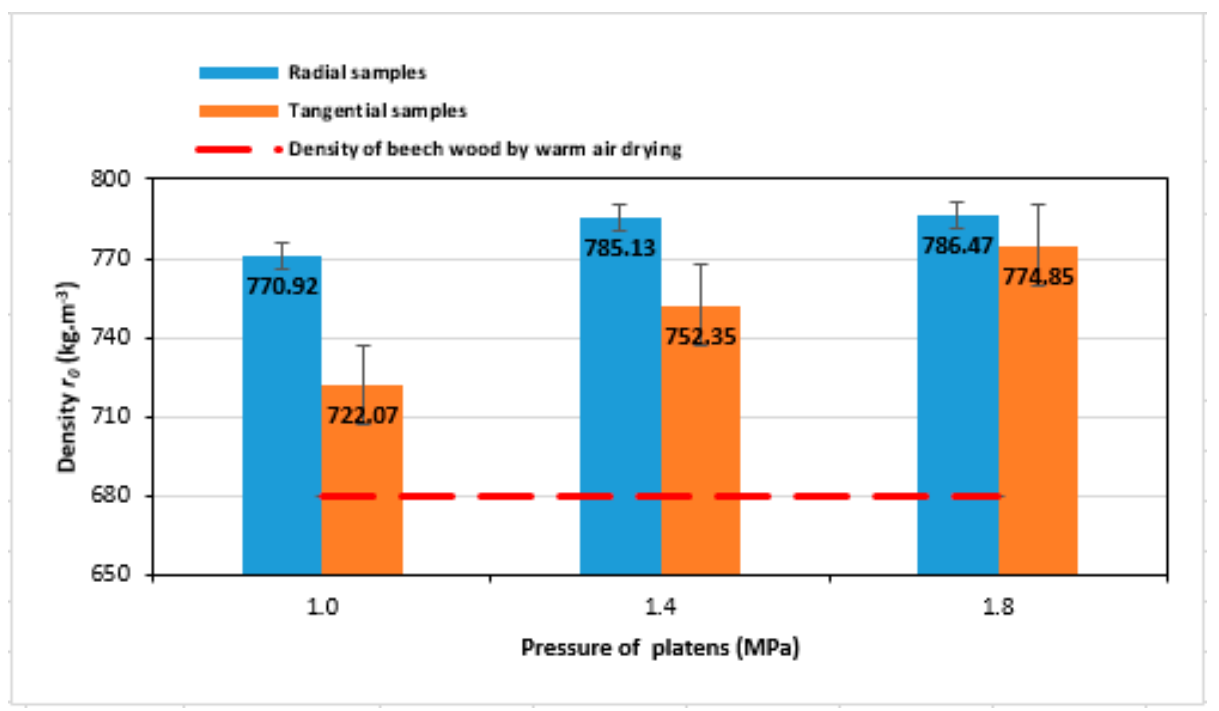

Figure 6. Average values of densities after drying.

The results of measuring the average density of the samples showed that higher values were measured in the case of the radial samples in comparison to the tangential samples after drying. The similar statements were mentioned by the author [12] who discovered that there can be an increase in density during contact-drying by even $10 \%$. The higher density was discovered in the radial and tangential samples from 40 up to $100 \mathrm{~kg} \cdot \mathrm{m}^{-3}$ with compared to beech wood by warm-air-drying. The difference is shown in Figure 6. Remarkable effect of the pressure of the heating plates on the change in density was observed in the case of the tangential samples (Figure 6). The changes in density were identified between the pressure of $1.0 \mathrm{MPa}$ to $1.8 \mathrm{MPa}$ in the case of the tangential samples. An increase in density by more than $50 \mathrm{~kg} \cdot \mathrm{m}^{-3}$ in the case of the tangential samples was determined. An increase in the case of the radial samples was only by about $10 \mathrm{~kg} \cdot \mathrm{m}^{-3}$. For a pressure of $1.8 \mathrm{MPa}$, the difference between the radial and tangential samples was not significant (Figure 6). The above mentioned measured values of density lead to the assumption that the radial samples underwent a larger dimensional change (Figure 6). We can suppose that the bigger increase in density in the radial samples caused the compression of the surface layer of the samples, which was thinner than in the tangential samples. In other works [6,10], similar increase in density in the surface layers of wood were discovered. Density of poplar wood increased to the value of $900 \mathrm{~kg} \cdot \mathrm{m}^{-3}$ from the original value of $400 \mathrm{~kg} \cdot \mathrm{m}^{-3}[6,10]$. The remarkable differences in the average density after drying did not result in any remarkable changes in width and length of the samples.

The change in thickness was observed in the case of all pressures compared to the thickness measured before drying. Figure 7 shows a decrease in the thickness from $3(10 \%)$ up to $6(20 \%) \mathrm{mm}$. The biggest changes of thickness of the radial and tangential samples were discovered in the case of the pressure of 1.8 MPa. According to the similar results [3,7,12] it is clear that the effect of contact-drying on changes in thickness are significant. Similar research studies $[7,12]$ showed reduction of thickness of about 8 up to $20 \%$ after contact-drying process. 


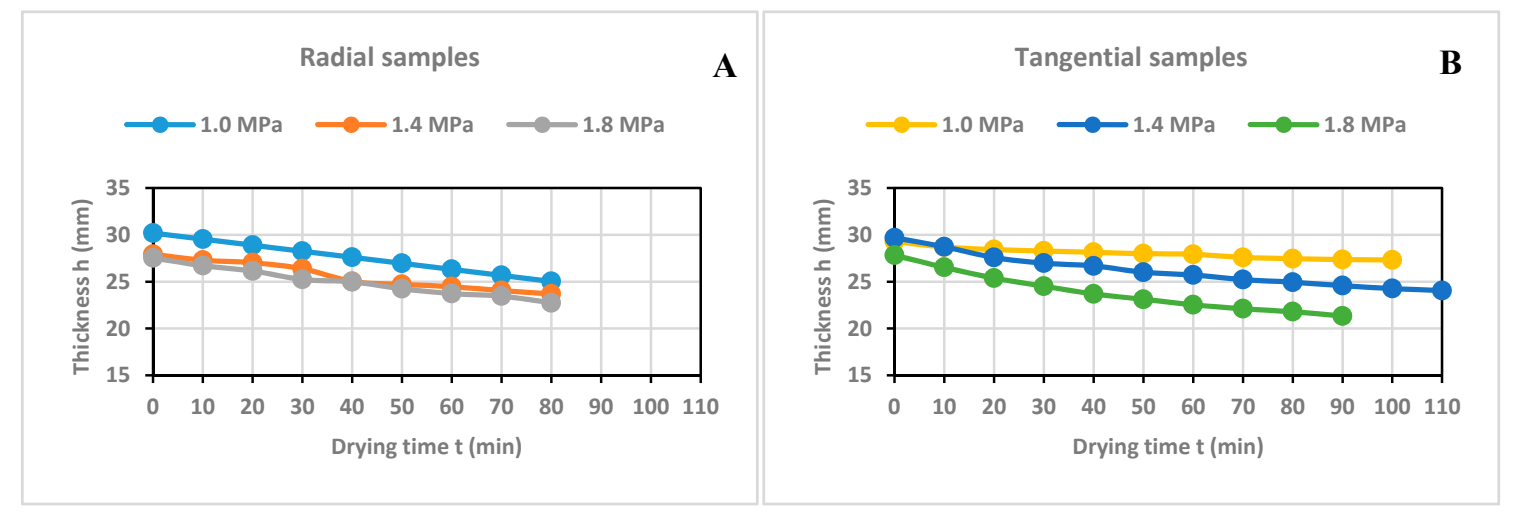

Figure 7. Change in the thickness in the (A) radial and (B) tangential samples during contact-drying.

The sample thickness did not change after conditioning (Figure 8). The largest difference of thickness was $0.39 \mathrm{~mm}$ after conditioning. The average values of the change in the thickness of the samples are shown in Figure 8.

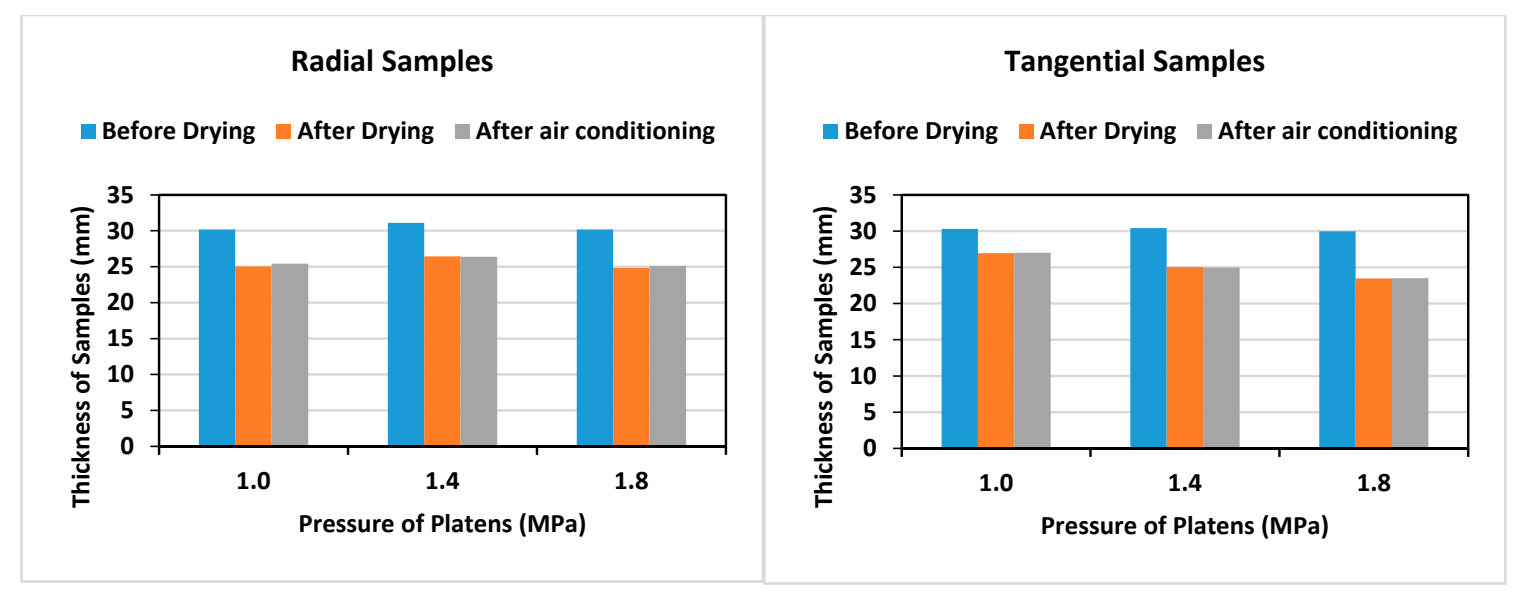

Figure 8. Average values of the sample thickness before drying, after drying and after air conditioning.

\section{Hygroscopicity of Wood}

The values of wood hygroscopicity at individual times for the selected pressures of the heating plates and for warm-air-drying are shown in Figure 9. The values of wood hygroscopicity for the samples dried by the contact method were lower compared to the samples dried by the warm-air process. It was also mentioned in the research [10] where wood hygroscopicity changed due to contact-drying process of poplar wood.

The results showed the effect of an increase in the pressure of the heating plates on a decrease in hygroscopicity (Figure 9). Significantly lower values were measured in the case of the tangential samples compared to the radial samples (Figure 10). Based on the results of [5] pressed surface layers of tangential samples contain extractives substance which could be the reason for lower values of hygroscopicity. These extractives can behave as hydrophobic substances decreasing the wood hygroscopicity. This statement was confirmed even by other research [5]. 


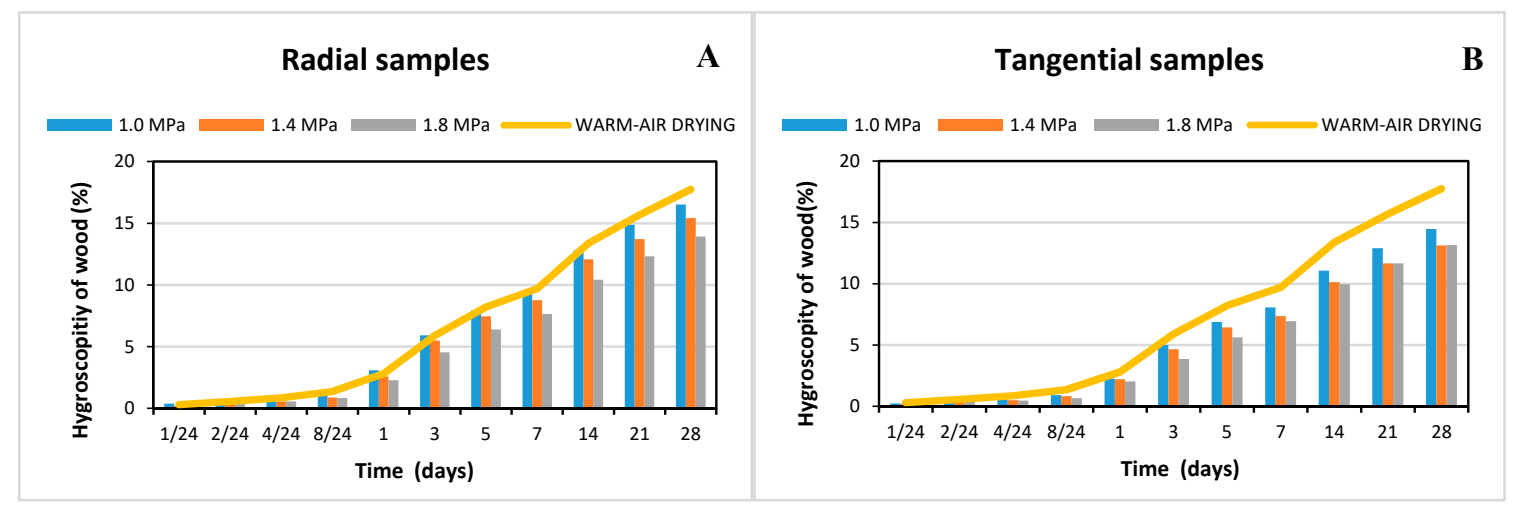

Figure 9. Development of wood hygroscopicity at time in the case of the (A) radial and (B) tangential samples.

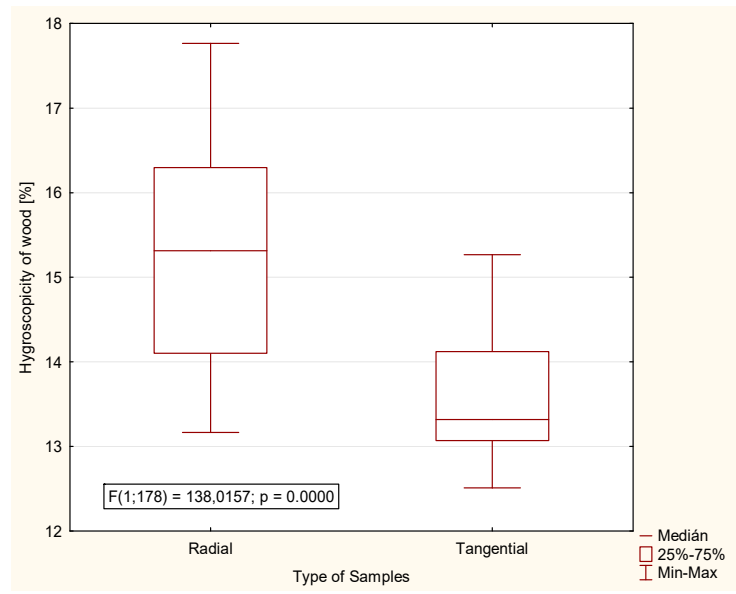

Figure 10. Impact type of sample on the values of wood hygroscopicity $(p<0.0000)$.

Significant difference between the measured values were discovered by testing the radial samples. (Figure 11A). Similar significant difference was discovered between the pressure of 1.0 MPa and 1.4 MPa in the case of the tangential samples. The difference between pressures of 1.4 and $1.8 \mathrm{MPa}$ were insignificant (Figure 11B).
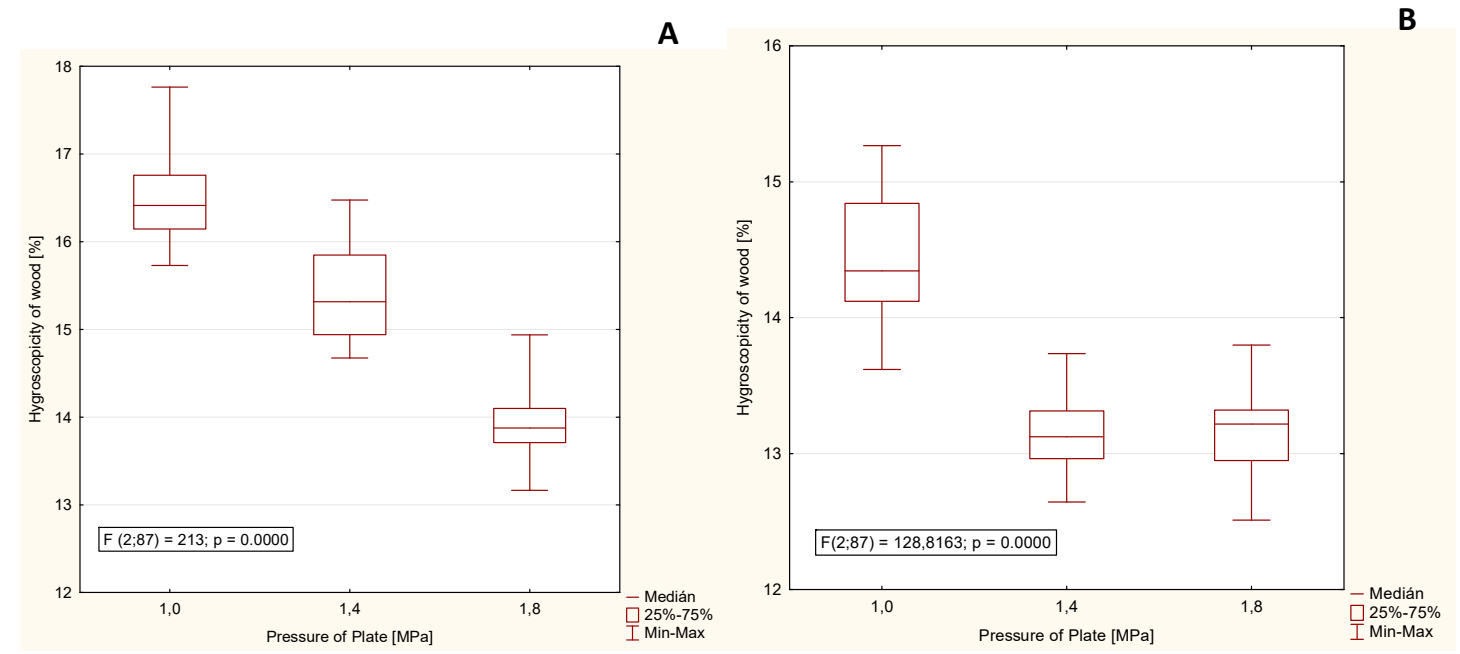

Figure 11. Effect of plate pressure on the resulting value of wood hygroscopicity for the (A) radial and (B) tangential samples. 
Generally, it can be stated that the average value of wood hygroscopicity was lower by about $21.24 \%$ compared to the samples dried by warm-air-drying. The assumption of the partial degradation of the polysaccharide wood components were confirmed. During the contact-drying, reducing the yields of hemicellulose towards the surface of the dried samples occurred. At higher pressure representing more intense effect on the polysaccharide content, there is a greater loss of holocellulose. These changes are mainly due to the degradation of the easily hydrolysable fraction of hemicelluloses of an amorphous nature [5]. The present observations are consistent with those of work [12] based on results gained by testing the poplar wood.

Absorptivity of Wood

The change in the ability of the samples to absorb water in the liquid state at an individual time for the selected pressures of the heating plates and in the warm-air-drying (TVZ) are shown in Figure 12.

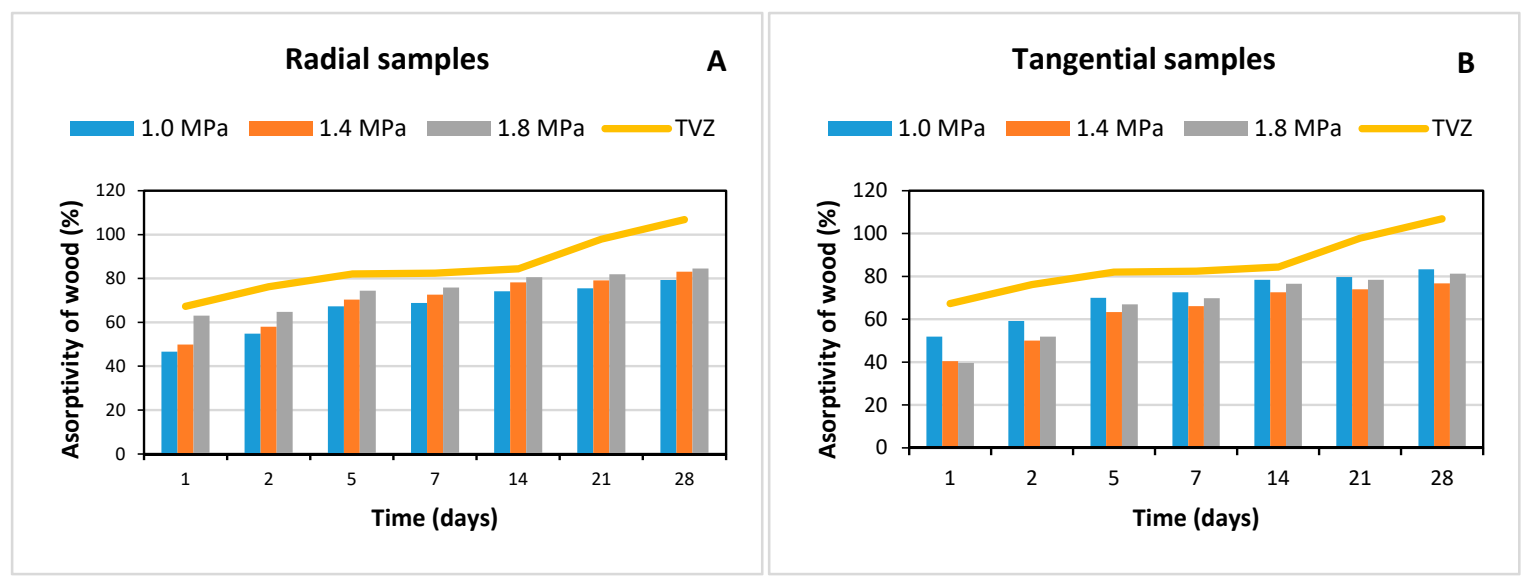

Figure 12. Development of the absorptivity of wood at time in the case of the (A) radial and (B) tangential samples.

The water absorption values of the samples were lower by $24.81 \%$ on average after contact-drying than during warm-air-drying. This remarkable difference was approximately the same during testing both, the radial and tangential samples. The remarkable reduction of absorptivity of wood as well as the difference between the radial and tangential samples (Figure 13) is due to the chemical changes in the degradation of the cellulose matrix [5].

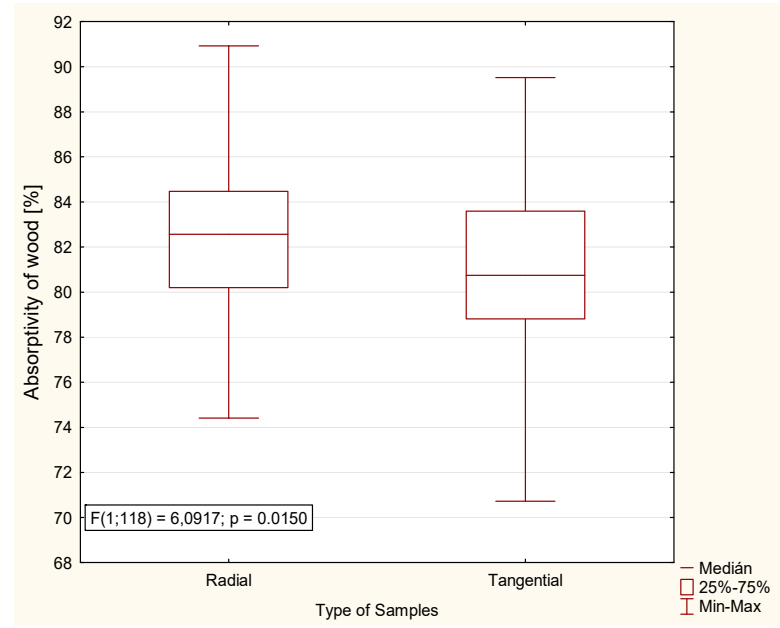

Figure 13. Effect of the sample on the resulting value of the absorptivity of wood $(p<0.05)$. 
The change in the absorptivity of wood was not significantly affected by the pressure of the heating plates. The effect of the radial and tangential samples was statistically significant at the level of significance $p<0.05$ (Figure 13).

\section{Conclusions}

The aim of the work was to discover the effect of the contact-drying on the change of selected physical properties of beech wood.

The following conclusions can be drawn from the measured data:

- The research proved that the pressure of the heating plates has no remarkable effect on the contact-drying time. The radial samples are dried faster than tangential ones, with a maximum difference of $30 \mathrm{~min}$.

- $\quad$ The measured values of the moisture gradients were high, the need for subsequent air conditioning of the samples was confirmed.

- An increase in density of the radial and tangential samples from 40 up to $100 \mathrm{~kg} \cdot \mathrm{m}^{-3}$ was discovered in comparison to the warm-air-drying. The density of the samples increased remarkably during contact-drying. The pressure of the heating plates had a substantial effect. The difference in the average density was more than $22 \mathrm{~kg} \cdot \mathrm{m}^{-3}$ between the pressure of $1.0 \mathrm{MPa}$ and $1.8 \mathrm{MPa}$. The density values were significantly higher in the case of the radial than in the tangential samples after contact-drying. The maximum difference was measured at a pressure of $1.0 \mathrm{MPa}$, where the difference in average density was $48.85 \mathrm{~kg} \cdot \mathrm{m}^{-3}$.

- $\quad$ The pressure of the heating plates affected the process and the resulting change in the thickness of the samples. The difference in the thickness change was larger in the case of the tangential samples. There was no change in the thickness of the samples after air conditioning.

- Wood hygroscopicity was changed by contact-drying by $21.24 \%$ on average compared to warm-air-drying. The average hygroscopicity of wood reduced by about $9 \%$ in the case of the tangential and by almost $16 \%$ in the case of the radial samples affected by contact-drying. The effect of heating plate pressure was remarkable in the case of the radial samples. Moreover, it was confirmed that the values of hygroscopicity of wood decrease when the pressure increases.

- The values of the wood absorptivity of the samples dried using the contact method were lower by almost $24.81 \%$ than in the case of the samples dried using the warm-air method.

- Absorptivity of wood increased due to the contact-drying and in the case of the radial samples by more than $6 \%$. The values of wood absorptivity reduced in the tangential samples at a compression pressure of $1.8 \mathrm{MPa}$ by almost $2.5 \%$ and at $1.4 \mathrm{MPa}$ by almost $8 \%$.

The contribution of the present publication is the verification of the contact-drying method, which belongs to the special drying modes. Contact-drying remarkably reduces drying time while modification some physical and mechanical properties. Wood which is dried by contact-drying can be used for furniture, sauna manufacturing, as a floor material and so forth.

Author Contributions: Conceptualization, I.K., P.V.; methodology I.K., T.V.; software, I.K., P.V.; validation, I.K., P.V., T.V.; formal analysis, I.K., P.V.; investigation, I.K., T.V.; resources, I.K., P.V.; data curation, I.K., T.V.; writing-original draft preparation, I.K., P.V.; writing—-review \& editing, P.V.; visualization, P.V., T.V. All authors have read and agreed to the published version of the manuscript.

Funding: This research was funded by the Slovak Research and Development Agency under the contract no. APVV-17-0583.

Conflicts of Interest: The authors declare no conflict of interest. 


\section{References}

1. Furst, C.; Seifert, T.; Makeschin, F. Do site factors affect the wood quality of European beech (Fagus sylvatica L.) Results from a pre-study on red heartwood. Forst Holz 2006, 61, 464-468.

2. Ross, R.J. Wood Handbook: Wood as an Engineering Material, Centennial Edition; U.S. Dept. of Agriculture, Forest Service, Forest Products Laboratory: Madison, WI, USA, 2010; p. 508.

3. Simpson, T.W. Maintaining lumber quality in press drying by manipulating sawing patterns. Wood Fiber Sci. 2007, 16, 411-426.

4. Bond, B.H.; Espinoza, O. A Decade of Improved Lumber Drying Technology. Curr. For. Rep. 2016, 2, $106-118$. [CrossRef]

5. Klement, I.; Trebula, P.; Dekrét, A. Influence of the Temperature and Moisture Fields in Hornbeam Wood on Its Physical and Chemical Alterations; Scientific Study; Technical University in Zvolen: Zvolen, Slovakia, 2001; p. 59. ISBN 80-228-1122-X.

6. Hou, J.; Yi, S.; Zhou, Y.; Pan, B. Moisture state variety in poplar lumber with moisture content above fibre saturation point during hot-press drying. J. Wood Sci. 2018, 64, 730-737. [CrossRef]

7. Hittemeier, M.E.; Comstock, G.L.; Hann, R.A. Press drying nine species of wood. For. Prod. J. 1968, 18, 91-96.

8. Stoker, D.L.; Pearson, R.G.; Kretschmann, D.E.; Tang, Y.; Simpson, B. Effect of press-drying on static bending properties of plantation-grown No. 2 loblolly pine lumbe. For. Prod. J. 2007, 57, 70.

9. Ouertani, S.; Koubaa, A.; Azzouz, S.; Hassini, L.; Dhib, K.B.; Belghith, A. Vacuum contact drying kinetics of Jack pine wood and its influence on mechanical properties: Industrial applications. Heat Mass Transf. 2014, 51, 1029-1039. [CrossRef]

10. Zhou, F.; Gao, X.; Fu, Z.; Zhou, Y. Drying kinetics of poplar lumber during periodic hot-press drying. Dry. Technol. 2018, 36, 1767-1780. [CrossRef]

11. Chen, P.Y.S.; Biltonen, F.E. Effect of Prefreezing on Press-Drying of Black Walnut Heartwood. For. Prod. J. $1979,29,48-51$.

12. Jung, S.H.; Lee, H.N.; Yeo, H. Press-drying of Plantation Softwood Lumber. J. Korean Wood Sci. Technol. 1993, 21, 61-66. 